\title{
Designing reading tasks to maximise vocabulary learning
}

\author{
Paul Nation \\ (Emeritus Professor, Victoria University of Wellington, New Zealand) \\ paul.nation@vuw.ac.nz
}

(Received: 31.10.2013, Accepted: 10.11.2013)

\begin{abstract}
Most vocabulary learning should occur incidentally through listening and reading. This is one of the reasons why a substantial extensive reading program is an important part of an English course. Extensive reading requires the learners to do large quantities of reading using material that is at the right level for them. Vocabulary learning occurs through the conditions of repetition, retrieval, creative use, and deliberate attention. These conditions can be maximized when reading through the use of narrow reading, repeated reading, linked skills reading, reading with discussion, and deliberate learning through reading with exercises. Computer-based activities can be effective in providing opportunities for deliberate learning, but it is important that deliberate learning does not take time away from extensive reading.
\end{abstract}

Keywords: vocabulary learning, conditions, extensive reading

\section{Introduction}

A well-balanced language course has opportunities for incidental learning and deliberate learning. Incidental learning occurs when learners are reading, writing, listening, or speaking with their attention focused on the message. In spite of the focus on the message, they manage to learn some new words and phrases or become familiar with some unknown or partly known grammatical constructions. Incidental learning can occur through meaning-focused input when the learners are listening or reading, through meaning-focused output when the learners are speaking or writing, or through fluency development activities in any of the four skills.

Most vocabulary learning for native speakers occurs as incidental learning. However, learners of English as a foreign language need extra support in order for incidental learning to occur. This is because foreign language learners do not usually get enough contact with the language and enough contact with language which is at the right level for them for incidental learning to occur. The purpose of this article is to look at how teachers can provide this support through the careful design of activities.

Let us first look in detail at a very effective reading activity to see what conditions for incidental learning it provides.

\section{Vocabulary learning from extensive reading}

Extensive reading for foreign language learners involves reading large quantities of material which has been specially written to be at the right vocabulary level for the learners. The books which are most suitable for extensive reading are called graded readers and every major ELT publisher has at least one and often several series of graded readers. For example, Cambridge University Press publishes the Cambridge 
English Readers which are original texts specially written at several vocabulary levels (see Table 1).

Table 1: Levels of the Cambridge English Readers series

\begin{tabular}{|c|c|c|c|}
\hline Level & $\begin{array}{l}\text { Different } \\
\text { words }\end{array}$ & $\begin{array}{l}\text { Approximate } \\
\text { length }\end{array}$ & $\begin{array}{l}\text { Example } \\
\text { titles }\end{array}$ \\
\hline $\begin{array}{l}\text { Level } \\
1\end{array}$ & $\begin{array}{l}400 \\
\text { words }\end{array}$ & $\begin{array}{l}4000 \\
\text { words }\end{array}$ & $\begin{array}{l}\text { Bad love, } \\
\text { Blood } \\
\text { diamonds }\end{array}$ \\
\hline $\begin{array}{l}\text { Level } \\
2\end{array}$ & $\begin{array}{l}800 \\
\text { words }\end{array}$ & $\begin{array}{l}10,000 \\
\text { words }\end{array}$ & $\begin{array}{l}\text { Apollo's } \\
\text { gold, } \\
\text { Jojo's } \\
\text { story }\end{array}$ \\
\hline $\begin{array}{l}\text { Level } \\
3\end{array}$ & $\begin{array}{l}1,300 \\
\text { words }\end{array}$ & $\begin{array}{l}15,000 \\
\text { words }\end{array}$ & $\begin{array}{l}\text { The } \\
\text { Beast, } \\
\text { Two lives }\end{array}$ \\
\hline $\begin{array}{l}\text { Level } \\
4\end{array}$ & $\begin{array}{l}1,900 \\
\text { words }\end{array}$ & $\begin{array}{l}20,000 \\
\text { words }\end{array}$ & $\begin{array}{l}\text { Berlin } \\
\text { express, } \\
\text { Staying } \\
\text { together }\end{array}$ \\
\hline $\begin{array}{l}\text { Level } \\
5\end{array}$ & $\begin{array}{l}2,800 \\
\text { words }\end{array}$ & $\begin{array}{l}25,000 \\
\text { words }\end{array}$ & $\begin{array}{l}\text { All I } \\
\text { want, } \\
\text { Tangled } \\
\text { web }\end{array}$ \\
\hline $\begin{array}{l}\text { Level } \\
6\end{array}$ & $\begin{array}{l}3,800 \\
\text { words }\end{array}$ & $\begin{array}{l}30,000 \\
\text { words }\end{array}$ & $\begin{array}{l}\text { A love for } \\
\text { life, } \\
\text { Murder } \\
\text { maker }\end{array}$ \\
\hline
\end{tabular}

For example, in level 2 of the Cambridge English Readers, all the books are written within the vocabulary of 800 words, so that if you know these words you can read the books with no difficulty. Note that the books are quite long, and this gives learners a lot of reading practice at a level which is easy enough for them. The books are written to be enjoyed and the stories are interesting and exciting.

Extensive reading can be carried out in the classroom (and it is best introduced by scheduling regular classroom time for it) or it can be carried out outside of class as a homework activity. The learners choose books which are interesting for them to read at a level which is just beyond their present vocabulary level so that there are some unknown words in the books but not too many. Ideally only around two words out of every 100 running words should be unfamiliar to the learners. The learners then read the books to enjoy the stories and may fill in a brief report form after reading each book, but otherwise they are not required to do any other assessment activities related to the reading. The goal is to do a large amount of enjoyable reading.

How does extensive reading help vocabulary learning? As learners read they will meet words that they only partly know or that they have not met before. Each meeting provides a small opportunity to learn about the form, meaning and use of the word within the contexts in which it occurs. After the first meeting with the word, the learners may meet the word again in the book and when they do they have a chance to recall what they learnt from the previous meeting. This recall is probably done subconsciously. Each time a learner meets a word and is able to successfully recall some information from previous meetings, this is called a retrieval. Spaced retrievals help learning.

Ideally, learners should read at least one graded reader every week because this allows newly met vocabulary a chance to occur again before the learners have forgotten the previous meeting with it (Nation \& Wang, 1999). Vocabulary learning is also helped if each meeting with the word is in some way different from the previous meetings (Joe, 1998). That is, if the word occurs again with a different inflection, in a slightly different grammatical context, in a different meaning context, or in a different collocation. Graded readers 
naturally provide these conditions. If we look at the occurrences of new words at a particular level in a graded reader (this can be done by running a computer text of the graded reader through a concordance program like AntConc or MonoPro), we find that such words typically occur in different contexts each time they occur. The different contexts help enrich knowledge of the words and make later retrievals easier. Sometimes when a learner meets an unknown word in a graded reader they are not able to guess its meaning from the context clues, and so the learner may look in a dictionary to find the meaning. Looking a word up in a dictionary is a form of deliberate learning and this can make a strong contribution to knowledge of the word.

Graded readers are texts written within a very controlled vocabulary. The main advantage of vocabulary control is that it excludes the many words that are well beyond the learners' present vocabulary level. If a learner tried to read an unsimplified text that was way beyond their proficiency level, they would meet hundreds of words that are unknown to them. Most of these words would only occur once in the text and would therefore act as a barrier to reading without having much chance of being learnt (Nation \& Deweerdt, 2001).

So, we can see that extensive reading naturally provides very supportive conditions for incidental vocabulary learning. By reading graded readers, learners meet a manageable number of unknown words in comprehensible contexts. By doing a reasonable amount of reading, they will have the chance to meet these words again and thus will have many opportunities to retrieve knowledge of the words that they have gained from previous meetings with them. They will also meet these words in a variety of contexts which will help enrich their knowledge of these words and increase their retention of them.

How can we maximise the vocabulary learning opportunities provided by extensive reading? The major way to maximise vocabulary learning from extensive reading is by getting the learners to do a lot of extensive reading. Ideally, just under one quarter of the time in a well-balanced language course should be spent doing extensive reading for meaning-focused input and fluency development (Nation \& Yamamoto, 2012). Vocabulary learning can also be maximized by making sure learners are reading books which are at the right level for them. In addition, vocabulary learning from extensive reading will be helped if the learners combine a little deliberate learning with the incidental learning. That is, when they meet some new words in their extensive reading, they can put them on word cards for later decontextualised study. Immediately they finish reading a graded reader, learners might like to spend a small amount of time to reflect back on any of the new words that they met during their reading.

\section{Learning conditions}

In this description of incidental vocabulary learning from extensive reading we have looked at several conditions which support learning. Firstly, we have the condition of repetition. It is clearly easier to learn something that is met several times than something that is just met once. Although there is no clear cut-off point for the minimum amount of repetitions needed for learning, there is plenty of evidence that the greater the number of repetitions, the more likely learning is to occur (Waring \& Takaki, 2003). Nation and Wang (1999) found that it was necessary to read several graded readers at the same level in order to meet all of the new words which were 
introduced at that level with enough repetitions for these to have a chance of being learnt.

Secondly, we have the condition of retrieval. Having an opportunity to recall something that has been met before strengthens learning. When meeting a word again in a graded reader, retrieval at least involves recognising the form of the word as being at least partly familiar and being able to recall the meaning or part of the meaning that was gained on previous meetings.

Thirdly, we have the condition of creative use (Joe (1998) calls it "generative use"). Creative use can be receptive or productive. Receptive creative use involves meeting a word through listening or reading in new contexts. Productive creative use occurs when a learner produces the word in speaking or writing using it in ways in which the learner has not met it or used it before.

Fourthly, we have the condition of deliberate attention. Deliberate attention means consciously focusing on the language item in order to understand or learn it. Deliberate attention occurs when we look up the word in a dictionary or in a glossary, or when we ask someone about the meaning of the word. As long as this does not interrupt the message-focused activity too much, deliberate attention is a very useful contributor to vocabulary learning.

Let us now look at a range of messagefocused reading activities to see how these conditions of repetition, retrieval, creative use, and deliberate attention can be maximised so that such reading not only provides pleasure and improvement in reading skills, but also contributes to vocabulary growth.

\section{Learning vocabulary through a range of reading activities}

We saw that one of the most important effects of writing graded readers within a strictly limited vocabulary is to greatly reduce the vocabulary burden of a text. Unsimplified text contains vocabulary from a very wide range of frequency levels from the first 1000 to beyond the $20^{\text {th }} 1000$. One way to reduce the vocabulary load without simplification is to do what is called narrow reading (Hwang \& Nation, 1989; Schmitt \& Carter, 2000). Narrow reading involves reading texts that are closely related to each other. Reading closely related texts does reduce the overall vocabulary load (Sutarsyah, Kennedy \& Nation, 1994), but it does this to only a small degree (see Webb \& Rodgers, 2009a \& b, for the effect of narrow listening on vocabulary load). It is thus an activity best suited to high intermediate and advanced learners who have a large enough vocabulary size to be able to cope with unsimplified text without a great deal of outside assistance. Narrow reading is especially useful for the learning of technical vocabulary, particularly when the learner can draw on background knowledge of the subject.

For beginning and intermediate learners, repeated reading is a useful activity. In repeated reading, the learner reads the same text three times. For native speakers of English, repeated reading is typically done orally with the learner reading a text of 150 or so words long to the teacher or to another more proficient learner. The time taken to read the text is written down, and immediately after the first reading, the text is then read again, and then finally once more. All three readings are within the same reading session. Repeated reading is aimed at developing reading fluency, but it also clearly sets out conditions which are useful for vocabulary learning. The repeated 
readings of the text mean that the vocabulary in the text is met three times. The readings occur one after the other and this means that retrievals should be relatively easy to make. The activity does not involve creative use. There is however a deliberate element to repeated reading, especially on the first reading of the text. It is during this first reading that any word recognition problems or problems with unknown vocabulary are dealt with. For more proficient learners, repeated reading can be done silently with the intention of gaining deeper comprehension of the text on each reading.

Reading can occur in a series of linked skill activities. In linked skill activities the learner works on the same content material at least three times, but each time using a different one of the listening, speaking, reading, and writing skills. For example, the learners might read the text, then talk about it to each other in small groups or in pairs, and then write the main ideas from it. In this example, the activity moves from reading to speaking to writing. There are clearly many combinations possible in linked skill activities. From a vocabulary learning perspective, linked skill activities provide excellent opportunities for repetition (the same material is worked on three times), retrieval (both productive and receptive), and creative use (the three tasks in the series in a linked skills activity are different, but are focused on the same content and make use of the same language items). In a linked skills activity, the last activity in the series is the one that is typically done with the greatest fluency because the learners now bring a lot of background knowledge and language knowledge to the task from the first two parts of the activity. If the linked skills activity involves a pair or group speaking phase, then there could be the opportunity for the negotiation of unknown vocabulary. Linked skills activities are very easy to prepare and provide the learners with a lot of useful work. A reading text is often a good starting point when designing such activities even though reading may be the second or third activity in the series.

Reading with discussion involves at least two learners reading the same text. The learners read to a predetermined point in the text, say for example to the end of the first paragraph. They then discuss what they have just read with their partner to clear up any problems in the reading. They then read the next part of the text silently and then discuss that. In this way the text is read making sure that a high level of comprehension is achieved (see Palincsar \& Brown, 1986, for a similar and more elaborate reading strategy). This activity clearly provides useful conditions for vocabulary learning. The discussion will recycle the vocabulary met in the text allowing an opportunity for retrieval, and because the discussion is not simply an oral repetition of the text, the vocabulary is likely to occur in slightly different contexts in the discussion. The discussion also has some deliberate elements in that it may be necessary in the discussion to directly discuss the meaning of words and constructions in order to gain clear comprehension.

The reading with discussion activity is a bit like having a text followed by exercises, except that the discussion should be largely comprehension focused. Reading with exercises has been researched as a way of encouraging vocabulary learning (Paribahkt $\&$ Wesche, 1996). The exercises provide opportunities for repetition, and, if they are thoughtfully designed, for retrieval and creative use. They are however usually directed towards deliberate learning, and with this activity we have moved to a large degree away from incidental learning. 
Tom Cobb's website (www.lextutor.ca) has a very useful Read with resources program. Text can be pasted into the website and the following resources can be drawn on.

1 Spoken form. Clicking once on any word provides the spoken form of the word. In a separate program under the Text-toSpeech heading on Cobb's web page, it is possible to link written texts to their spoken form where this exists.

2 Examples in context. Clicking twice on a word brings up several instances of the word in context (a concordance), like the one for the word laugh (see appendix).

These extra contexts can be used to help guess the meaning of the unknown word, to gain information about the use of the word (grammar and collocates), and to gain information about the range of senses of the word.

3 Meaning. Clicking on a link brings up a substantial dictionary entry for a word from a range of possible dictionaries including learner dictionaries.

4 Revision. Holding down the Altkey and clicking puts the word in a box at the top of the screen for later revision. These revision activities can include (a) a dictation test where the word is heard and the learner has to write the word, (b) a meaning test where a concordance appears but the pivot word is missing and must be chosen from the list in the box (Nation, 2008).

Reading with resources provides a range of deliberate focuses which result in repeated attention to the words. The examples in context provide plenty of receptive creative use.

We have looked at a range of reading activities including those which are completely message-focused to those which have strong deliberate learning features. It is not too difficult to add deliberate learning features to reading, but it is important that the teacher's skill is also directed towards making sure that message-focused reading is also providing useful conditions for vocabulary learning. The major ways in which this can be done involve using graded material which is at the right level for the learners, ensuring that the learners do large amounts of reading, providing recycling of the vocabulary through repeated meeting of the content as in repeated reading and linked skills activities, and by providing occasional deliberate language focuses through the use of dictionaries, glossaries, hypertext, concordances, and vocabulary exercises. It is important that the deliberate language focus is not overdone at the expense of quantity of message-focused reading.

\section{References}

Hwang, K., \& Nation, P. (1989). Reducing the vocabulary load and encouraging vocabulary learning through reading newspapers. Reading in a Foreign Language, 6(1), 323-335.

Joe, A. (1998). What effects do text-based tasks promoting generation have on incidental vocabulary acquisition? Applied Linguistics, 19(3), 357-377.

Nation, I. S. P. (2008). Teaching vocabulary: strategies and techniques. Boston: Heinle Cengage Learning.

Nation, I. S. P., \& Deweerdt, J. (2001). A defence of simplification. Prospect, 16(3), 55-67.

Nation, P., \& Wang, K. (1999). Graded 
readers and vocabulary. Reading in a Foreign Language, 12(2), 355-380.

Nation, I.S.P. \& Yamamoto, A. (2012). Applying the four strands. International Journal of Innovation in English Language Teaching and Research, 1(2), 167-181.

Palincsar, A. S., \& Brown, A. L. (1986). Interactive teaching to promote independent learning from text. The Reading Teacher, 40, 771-777.

Paribakht, T. S., \& Wesche, M. B. (1996). Enhancing vocabulary acquisition through reading: a hierarchy of textrelated exercise types. Canadian Modern Language Review, 52(2), 155-178.

Schmitt, N., \& Carter, R. (2000). The lexical advantages of narrow reading for second language learners. TESOL Journal, 9(1), 4-9.

Sutarsyah, C., Nation, P., \& Kennedy, G. (1994). How useful is EAP vocabulary for ESP? A corpus based study. RELC Journal, 25(2), 34-50.

Waring, R., \& Takaki, M. (2003). At what rate do learners learn and retain new vocabulary from reading a graded reader? Reading in a Foreign Language, 15(2), 130-163.

Webb, S., \& Rodgers, M. P. H. (2009a). The lexical coverage of movies. Applied Linguistics, 30(3), 407-427.

Webb, S., \& Rodgers, M. P. H. (2009b). The vocabulary demands of television programs. Language Learning, 59(2), 335-366. 


\section{Appendix: The word 'laugh' in context}

... don't talk about you.' 'I know you'll <laugh> at me,' replied Basil, 'but I can't ...

... much of myself into it.' Lord Henry <laughed>. 'Too much of yourself into it! You don't ...

... the secret of my heart.' Lord Henry <laughed>. 'And what is this secret of your heart ...

... Later, Lady Brandon introduced us. We <laughed $>$ at something that she said, and became ...

... Basil. 'You have to introduce me now,' <laughed> Lord Henry. Basil turned to him. 'Dorian ... ... are very amusing, of course, but you <laugh > at serious things. Don't take him away ... ... suit you.' 'Oh, it doesn't matter,' <laughed> Dorian. 'But it should matter to you, ... ... picture could grow old.' Lord Henry <laughed>. 'I don't think you would like that, ... ... happy to escape from it.' 'They say,' <laughed> the man next to Lady Agatha, 'that when ... ... Coloured birds around the room. People <laughed $>$, and smiled, and told him that he ... 